\title{
Software Process Improvement Programs: What happens after official appraisal?
}

\author{
Regina Albuquerque \\ Graduate Program in Informatics - \\ Pontifícia Universidade Católica do \\ Paraná (PUCPR), Curitiba - Paraná \\ - Brazil \\ Regina.fabia@pucpr.br
}

\author{
Andreia Malucelli \\ Graduate Program in Informatics - \\ Pontifícia Universidade Católica do \\ Paraná (PUCPR), Curitiba - Paraná \\ - Brazil \\ malu@ppgia.pucpr.br
}

\author{
Sheila Reinehr \\ Graduate in Informatics - Pontifícia \\ Universidade Católica do Paraná \\ (PUCPR), Curitiba - Paraná - Brazil \\ sheila.reinehr@pucpr.br
}

\begin{abstract}
Studies of critical success factors in the implementation of programs of software process improvement have been conducted on a large scale in recent decades. However, these studies only focus on the implementation and do not consider the factors that influence the continuity or abandonment of these programs after official appraisal. Therefore, the objective of this study is to investigate the critical factors involved in the maintenance or abandonment of these programs. For this purpose, an exploratory survey was conducted, with the participation of consultants and appraisers of software process improvement reference models. The result was the proposal of a theoretical framework of critical success factors to maintain the use of processes of reference models, composed of the following categories: human factors, project factors, consultancy, organizational factors and technical factors involved in the process.
\end{abstract}

Keywords: Software Process Improvement, continuity of SPI, abandonment of SPI.

\section{INTRODUCTION}

Since NATO meeting that was held in 1968 , where the term software engineering was born, the field has evolved significantly in terms of methods, tools and programming languages [1]. Several paths have been taken by both practitioners and researchers during this evolution. One of them concerns the belief that the quality of the software development process directly influences the quality of the resulting software product [2]. Based on this assumption several models to support software process improvement (SPI) were developed [3], especially those based on the concepts of maturity and capability, such as CMMI-DEV (Capability Maturity Model Integration for Development) [4]. Nowadays, there are also reference models that are highly recognized in their home country such as MR-MPS-SW (Brazilian Software Process Improvement Model) [5] and MoProSoft (the Mexican Model for Software Process) [6].

In 2003 the MPS.BR (Brazilian Software Process Improvement Program) was created by SOFTEX (Association for Promoting the Excelence of Brazilian Software) to support small and medium software organizations in the journey of SPI. The program is based on five core components [5]: Reference Model for Software (MR-MPS-SW), Reference Model for Services (MR-MPS-
SV), Reference Model for Human Resources Management (MR-MPS-RH), Assessment Method (MA-MPS) e Business Model (MN-MPS).

The reference model called MR-MPS-SW is focused on software processes and is equivalent to CMMI-DEV [15]. Both define maturity levels that establishes process evolution patterns, characterizing stages of improvement in the implementation of processes in an organization.

To facilitate the adoption of the model by the Brazilian software companies, MR-MPS-SW has seven maturity levels (starting at level $\mathrm{G}$, the lowest one, and progressing up to level A): A (Optimizing) corresponds to CMMI-DEV Level 5; B (Quantitatively Managed) corresponds to CMMI Level 4; C (Defined), D (broadly defined) and E (partially defined) correspond to CMMI level 3; F (Managed) and G (Partially Managed) are equivalent to CMMI-DEV level 2.

The cooperative business model is a hiring modality that stands out because it has the financial support of the Brazilian federal government (it has already reached the mark of 10 million), allowing companies to be organized in groups, sharing costs of training and implementation.

Organizations adopting such reference models are submitted to an official assessment to attest their process maturity level. In the case of CMMI-DEV, the appraisal model is called SCAMPI [4]. In the case of MR-MPS-SW, que appraisal method is called MA-MPS. Based on the results of the appraisal, organizations can plan changes to their process aiming at reaching better business results [7]. In both cases, an appraisal expires after 3 years.

In seeking maturity in their development processes, organizations often modify their management style. This change can impact positively on the results of software projects. For example, according to [8][9] some benefits can be observed such as the improvement on the predictability of cost and schedule estimates.

Although some very promising results of implementing such models have been described, there are some challenges on the way. As stated by [10], "understanding how to implement software process improvement (SPI) successfully is arguably the most challenging issue facing the SPI field". The finding of this difficulty was the motivation to carry out a significant number of researches on critical success factors for SPI initiatives, as seen in the systematic literature reviews (SLR) [11] [12]. 
Although there are some studies [13] [14] aiming to understand what influences the continuity of SPI programs after the official appraisal, there are several open questions such as: why do some organizations start at the lower maturity levels and do not evolve to a higher one? Why several organizations do not renew their appraisals when they expire? What really happen to the assessed processes after the official assessment: are they still up and running? Are they abandoned? Are they still been improved? There is, therefore, a need for more research that explores different cultural and organizational contexts, as well as the publication of experience reports from the software industry on the continuous improvement of software processes.

In this context, the objective of this study was to understand what makes it difficult and easier to maintain these SPI programs in software companies evaluated. To answer this question, a survey was conducted with SPI specialists. The results indicate that the continued use of SPI programs is related to human factors, the SPI project itself, organizational factors, consultancy and processes.

The study is organized into five sections. Section II presents the theoretical basis; section III the research method; section IV the results and the final considerations in section V.

\section{BACKGROUND}

As discussed in the introduction there is a dearth of studies on continuity of SPI programs. Therefore, it was decided to carry out a systematic literature review (SLR) on the implementation of SPI programs. The study followed the steps defined in Kitchenham [16]: (i) planning, (ii) identification, and (iii) the selection of primary studies.

The research protocol was defined in the planning phase (purpose of the review, research questions, inclusion and exclusion criteria, and evaluation of the selected studies). The research questions were defined: i) Which factors positively influence the implementation of software process improvements? and; ii) Which factors negatively influence the implementation of software process improvements?

In the identification phase, the search for relevant studies was carried out in the electronic bases of the ACM Digital Library, IEEE Explore, Science Direct and Springer Link, from December/2012 to January/2013, with supplementation in May/2014. The search period comprised the years 2002 to 2013. Publications were considered in journals and conferences, written in English. These procedures identified 2,474 articles.

The articles were selected considering three main activities i) reading of the titles of the articles; ii) reading of the abstracts of the articles and; iii) reading of whole article. Exclusion criteria were secondary articles and primary articles not related to implementation of SPI programs. The exclusion of these items was carried out in pairs, resulted in 51 papers which were analyzed with the open and axial coding procedures from the Grounded Theory [17]. The validation was done by specialists in SP, who performs implementations and assessments of maturity models.

The analysis of the studies from the systematic review resulted in 03 conceptual categories on success factors in the implementation phase of SPI: 35 Properties of Critical Success Factors (PCSF); 13 Critical Success Factors and; 04 macro categories of Critical Success Factors. Figure 1 shows the Critical Success Factors (CSF) grouped by macro categories of CSF, as show Table 1.

Table 1. Classification of Critical Success Factors.

\begin{tabular}{|c|c|c|}
\hline Categories & Critical Success Factor & CSF Properties \\
\hline \multirow{3}{*}{$\underset{\Xi}{\Xi}$} & Motivation and acceptance of change & Acceptance of change; Motivation for change. \\
\hline & Support, commitment and involvement & Support, commitment and involvement (senior management and employees). \\
\hline & Technical and personal skills & Technical and methodological skills; Personal skills (behavioral skills, attitudes and behaviors). \\
\hline \multirow{3}{*}{ 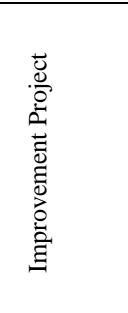 } & Implementation strategies & $\begin{array}{l}\text { Training; SPI project management; Adaptation of the SPI to the needs of the company; Gradual } \\
\text { implementation of improvement project; Definition of implementation strategy; Consideration of } \\
\text { culture (regional and organizational); Pilot projects; Selection of suitable professional for improvement. }\end{array}$ \\
\hline & Resources & $\begin{array}{l}\text { Availability of human resources; Availability of infrastructure resources; Availability of financial } \\
\text { resources; Availability of external resources (consultancy). }\end{array}$ \\
\hline & Adequate consultancy & $\begin{array}{l}\text { Relationship of trust between consultancy and company; Adequate consultancy work; Easy access of } \\
\text { the company team to the consultancy. }\end{array}$ \\
\hline \multirow{6}{*}{ 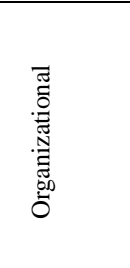 } & Communication & Adequate communication; Awareness of benefits. \\
\hline & Goals & SPI goals aligned to the business; Clear and relevant SPI goals. \\
\hline & Leadership & Existence of SPI leadership \\
\hline & Internal and external policies & Internal policies that support SPI; External policies that support SPI. \\
\hline & Organizational structure & Formalization of functions and responsibilities; Stable business environment. \\
\hline & Return on investment & Visibility of return on investment. \\
\hline
\end{tabular}




\begin{tabular}{|c|c|c|}
\hline 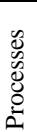 & Processes & $\begin{array}{l}\text { Standardization of new processes; } \\
\text { Monitoring of new processes; } \\
\text { Institutionalization of new processes, and metrics. }\end{array}$ \\
\hline
\end{tabular}

\section{SURVEY}

This is an exploratory study and, as such, it aims to provide a better understanding of the theme [18]. The research question that directed this work was: "What are the factors that influence the maintenance or abandonment of SPI programs?". For this purpose, a survey was conducted involving consultants and appraisers of software processes in order to assess the factors found in the literature and identify new factors in the field. The study followed the script proposed by Kitchenham et al. [19], establishing the activities described in the following sections.

\section{A. Identifying the research goals}

The aim of this study was to identify which factors of implementation identified in the systematic literature review, influence the maintenance or abandonment of software process improvement programs.

\section{B. Identifying and Projecting the Sample}

The population of this study was composed of Brazilian consultants and appraisers of the MPS.BR program, accredited by SOFTEX, and consultants and appraisers of the CMMI models. To identify the sample, a search was made from the SOFTEX website (http://www.softex.br), which identified 473 consultants and 124 appraisers of the MPS.BR program, affiliated with SOFTEX at the time of the research. However, an attempt was made to select a sample of professionals who were effectively exercising process improvement activities. A selection of professionals involved in the MR-MPS-SW model was conducted. This was based on the document entitled Result of Software Process Appraisal, which contains all the information of the appraisal conducted at the company, including the name of the lead appraiser and the assistant appraiser(s). This document is published on the SOFTEX website in the section on current appraisals of the model, for each company successfully appraised for the MR-MPS-SW and with an up-to-date appraisal, i.e., conducted in the last three years. From this search, there are currently thirty professionals involved in appraising the MPS.BR program in Brazil.

\section{Preparing the Questionnaire}

The questionnaire was developed based on the implementation of the SPI identified in the SLR. It was divided into two sections. The first contained six objectives and subjectives questions to characterize the professional by his experience. The second was divided into two parts: factors with a positive influence and factors with a negative influence. The questionnaire in Portuguese is available at https://pucpr.co1.qualtrics.com/jfe/form/SV_ehaV0rvIW5B 4wrb.
For the factors with a positive influence, the following question was asked: "In your opinion, to what extent does each factor contribute in practice when appraised companies maintain the use of the defined process? "For each factor, the respondents were offered three evaluations levels of the Servqual method [20]: minimum acceptable level, maximum desirable level and perceived level. These factors were assessed using the degree of importance according to a scale that varied from 1 (least relevant) to 9 (most relevant).

In this method, the interval between the mean of the acceptable minimum level and the mean of the desired maximum level is called the tolerance range, that is, it comprises values not perceived by the evaluator as being acceptable for the performance of that indicator. In this study, we consider that the factors with averages situated within the tolerance range, are factors perceived by the respondents as performed in the organizations practice. Factors with averages below the tolerance range indicate that these factors are not performed in the organizations' daily lives.

For the factors with a negative influence, the following question was asked: "In your opinion, to what extent does each factor contribute in practice when companies abandon their processes?" For this evaluation, a 9-point Likert scale was shown, starting with minimum value 01 (Totally disagree) to maximum value 9 (Totally agree). The respondents could also add other factors that they considered relevant for both maintenance and abandonment of SPI programs, using as open answer box.

The last section of the questionnaire included a confidentiality agreement, ensuring that the individual information would not be made public.

\section{Application of the pilot test}

Before forwarding the questionnaire to the target public, a pilot test was conducted with one consultant of the CMMIDEV model and one of the MR-MPS-SW model to evaluate the tool and the content of the questionnaire. The questionnaire was then distributed using a link sent by e-mail.

\section{E. Validity threats}

Regarding content validity in the design of the instrument [18], a pilot survey was conducted with the aim of evaluating whether the questions were easily understood and whether the degree of information provided by the questionnaire was appropriate. The participants reviewed the questionnaire and suggested some small changes to wording, aiming to facilitate understanding.

External validity refers to the conditions of generalization, i.e. the representativeness of the sample and the correspondence between respondents and the unit of analysis. Thus, to avoid inconsistent responses on the problem, 
respondents that were practitioners and experienced in SPI programs were identified.

\section{IDENTIFICATION OF PERCEPTION OF SPI EXPERTS}

\section{A. Professional Profile}

Twenty-one SPI specialists (representing $70 \%$ of the sample) participated in the study. The professionals were characterized by their experience in implementations and assessments. We consider as experienced the specialists who performed more than five implementations and/or assessments. We identified 18 experienced consultants and 14 lead appraisers in the MR-MPS-SW model and 09 consultants and 04 experienced appraisers in the CMMI-DEV model.

We identified that the total number of implementations performed by these professionals up to the time of the survey totaled 485 implementations in the MR-MPS-SW model ( $84 \%$ of the total assessments performed in the country) and 100 implementations in the CMMI model $(45 \%$ of the country's total assessments). This shows that the sample of the participants is very representative in relation to the total evaluations of the maturity models implemented in the country.

\section{B. Critical Maintenance Factors (CMF)}

This section will present the analysis of the data found, considering the three levels of evaluation for each factor of the SERVQUAL method.

Table 2 shows the experts' perception for the maintenance factors (positive influence) of the category of "human factors" for the post-evaluation period. Regarding the minimum acceptable, human factors are in a range of importance with a value higher than 05 , the average of the method, and under 07, which reinforces the importance attributed to these factors. For the Perceived Level, only factors of support senior management and employees are slightly above the minimum acceptable. The other factors are below the minimum acceptable, indicating that, according to the perception of the respondents, in practice the organizations are not paying due attention to these issues.

TABLE 2. Critical Maintenance Factors: Human.
\begin{tabular}{|l|c|c|c|}
\hline \multicolumn{1}{|c|}{ Maintenance Factor } & \multicolumn{3}{c|}{ SERVQUAL } \\
\cline { 2 - 4 } & NMA & NID & NP \\
\hline Support of senior management & 6,67 & 8,62 & 6,71 \\
\hline Support of employees & 6,19 & 8,24 & 5,67 \\
\hline Technical and methodological skills & 5,86 & 7,71 & 5,57 \\
\hline $\begin{array}{l}\text { Personal skills (behavioral skills, attitudes } \\
\text { and behaviors) }\end{array}$ & 6,05 & 7,95 & 5,71 \\
\hline Acceptance of change & 6,61 & 8,44 & 6,22 \\
\hline Motivation for change & 6,10 & 8,15 & 5,70 \\
\hline
\end{tabular}

Table 3 shows the experts' perception for the maintenance factors (positive influence) of the category of "process". It is worth noting that the standardization of new processes was the only factor within the zone of tolerance with the score for the Maximum Desired Level (6.43) and the Minimum Acceptable Level (6.29). The easy processes obtained a high score for the Maximum Desired Level (8.52) and low for Perceived Level (5.88), indicating that this factor is considered important but in practice, this does not occur in the organizations.

TABLE 3. Critical Maintenance Factors: Process.
\begin{tabular}{|l|c|c|c|}
\hline \multicolumn{1}{|c|}{ Maintenance Factor } & \multicolumn{3}{|c|}{ SERVQUAL } \\
\cline { 2 - 4 } & NMA & NID & NP \\
\hline Standardization of new processes & 6,29 & 8,05 & 6,43 \\
\hline Monitoring of new processes & 6,90 & 8,62 & 6,19 \\
\hline Institutionalization of new processes & 7,05 & 8,81 & 6,38 \\
\hline Adequate processes (Easy) & 6,94 & 8,52 & 5,88 \\
\hline Adequate metrics & 6,67 & 8,71 & 5,38 \\
\hline
\end{tabular}

Table 4 shows the experts' perception for the maintenance factors (positive influence) of the category of "SPI project". Only the Definition of SPI project implementation strategy had a score slightly higher than the minimum acceptable (6.05) for the Perceived Level (6.14). Nevertheless, it is worth emphasizing that the score for the Perceived Level is very close to the minimum acceptable. This indicates that despite being present in the organizations, it is not sufficient to ensure the use of the processes. The factors with the lowest Perceived Level values are Consideration of regional culture (5.33) and Conducting a pilot project for new processes (5.90). The values of the remaining factors were higher than 06 for Perceived Level.

TABLE 4. Critical Maintenance Factors: SPI project.

\begin{tabular}{|l|c|c|c|}
\hline \multicolumn{2}{|c|}{ Maintenance Factor } & \multicolumn{3}{|c|}{ SERVQUAL } \\
\cline { 2 - 4 } & NMA & NID & NP \\
\hline Definition of implementation strategy & 6,05 & 8,29 & 6,14 \\
\hline SPI project management & 6,67 & 8,52 & 6,05 \\
\hline Consideration of culture organizational & 6,48 & 8,14 & 6,05 \\
\hline Consideration of culture regional & 5,71 & 7,35 & 5,33 \\
\hline Training & 6,57 & 8,29 & 6,05 \\
\hline Adaptation of the SPI to the needs of the company & 7,00 & 8,60 & 6,60 \\
\hline Gradual implementation of SPI & 6,50 & 8,27 & 6,27 \\
\hline Availability of human resources & 7,10 & 8,76 & 6,14 \\
\hline Availability of financial resources & 6,95 & 8,57 & 6,29 \\
\hline Availability of external resources & 6,35 & 8,20 & 6,15 \\
\hline Selection of suitable professional for improvement & 6,38 & 8,48 & 6,00 \\
\hline Pilot projects & 6,48 & 8,33 & 5,90 \\
\hline
\end{tabular}

Table 5 shows the experts' perception for the maintenance factors (positive influence) of the category "Organizational factors". SPI goals aligned to the business and Existence of leadership scored higher for the ideal level (8.71). For the perceived level, the factors with the lowest scores were: Consciousness on benefits (5.81), ROI visibility (5.19), 
communication (5.62) and internal support policies (5.52), which indicates that in practice they may be neglected. External support policies had the lowest score for the acceptable minimum level (5.35), which indicates that in the opinion of experts, this factor is not as important for continuity of RLS programs.

TABLE 5. Critical Maintenance Factors: Organizational

\begin{tabular}{|l|c|c|c|}
\hline \multicolumn{2}{|c|}{ Maintenance Factor } & \multicolumn{3}{c|}{ SERVQUAL } \\
\cline { 2 - 4 } & NMA & NID & NP \\
\hline Awareness of benefits & 7,00 & 8,67 & 5,81 \\
\hline Adequate communication & 6,71 & 8,48 & 5,62 \\
\hline Formalization of functions and responsibilities & 7,10 & 8,76 & 6,38 \\
\hline Ambiente empresarial estável & & & \\
\hline Internal policies that support SPI & 6,40 & 8,40 & 6,10 \\
\hline External policies that support SPI & 6,43 & 8,10 & 5,52 \\
\hline Existência de liderança & 5,35 & 7,63 & 6,05 \\
\hline SPI goals aligned to the business & 7,00 & 8,71 & 6,48 \\
\hline Clear and relevant SPI goals & 6,86 & 8,71 & 6,00 \\
\hline Visibility of return on investment & 6,81 & 8,57 & 6,05 \\
\hline
\end{tabular}

\section{Critical Abandonment Factors (CAF)}

This section shows in ascending order for the average of the factors that the specialists identify the possible causes for the abandonment of SPI programs. The results are presented below by category.

In the "Human Factors" category (Table 6), the factors had average scores higher than 06 . Therefore, all the factors in this category are considered to influence the abandonment of SPI. It is worth highlighting that the lack of support from the upper management was considered the most critical factor in the abandonment of these initiatives (8.19). This was followed by the time/commercial pressures factor (7.75) and Work load (7.52). This shows that the specialists perceive that a lack of adequate support from the upper management and pressures at work on the executors of the process are factors that hinder the continuation of process improvements.

TABLE 6. Critical Abandonment Factors: Human.

\begin{tabular}{|l|c|c|}
\hline \multicolumn{1}{|c|}{ Critical Abandonment Factor } & Avg. & $\begin{array}{c}\text { Standard } \\
\text { Deviation }\end{array}$ \\
\hline $\begin{array}{l}\text { Lack of technical and methodological } \\
\text { competencies }\end{array}$ & 6.05 & 1.50 \\
\hline Lack of personal competencies & 6.10 & 1.45 \\
\hline Resistance from employees & 6.43 & 1.75 \\
\hline Low employee motivation & 6,71 & 1.68 \\
\hline Lack of employee involvement & 6.95 & 1.24 \\
\hline Bad/negative experiences & 7.15 & 1.67 \\
\hline Imposition & 7.25 & 1.69 \\
\hline Work load & 7.52 & 1.50 \\
\hline Time/commercial pressures & 7.75 & 1.49 \\
\hline Lack of support from upper management & 8.19 & 1.25 \\
\hline
\end{tabular}

Processes category shown in Table 07 , all the factors were considered critical to the abandonment of SPI programs. The factor with the lowest average (5.67) was Reduced creativity, and the factor with the highest average (8.05) was Lack of monitoring. Four factors had averages higher than 07:
Inadequate metrics, Extensive documentation, Bureaucracy and Complex processes.

TABLE 7. Critical Abandonment Factors: Processes.

\begin{tabular}{|l|c|c|}
\hline \multicolumn{1}{|c|}{ Critical Abandonment Factor } & Avg. & $\begin{array}{c}\text { Standard } \\
\text { Deviation }\end{array}$ \\
\hline Reduced creativity & 5.67 & 2.76 \\
\hline Lack of standardization & 6.19 & 1.69 \\
\hline Complicated framework & 6.67 & 2.37 \\
\hline Lack of flexibility & 7.00 & 1.82 \\
\hline Inadequate metrics & 7.19 & 1.75 \\
\hline Extensive documentation & 7.29 & 1.65 \\
\hline Bureaucracy & 7.33 & 2.01 \\
\hline Complex processes & 7.38 & 1.20 \\
\hline Lack of monitoring & 8.05 & 1.12 \\
\hline
\end{tabular}

The SPI project category is shown in Table 08 . To the respondents, the most critical abandonment factors were: Lack of consideration for organizational culture $(7,60)$ and Lack of human resources (7.52), with average values very close to 08 on the evaluation scale. The least influential factor for the abandonment of SPI programs was Implementation on a large scale (large scope of the improvement project causing coordination problems) (5.75). The considering regional culture factor (4.64) was not considered critical to the abandonment of SPI. The other factors scored over 06 and 07 on the evaluation scale.

TABLE 8. Critical Abandonment Factors: SPI Project.

\begin{tabular}{|l|c|c|}
\hline \multicolumn{1}{|c|}{ Critical Abandonment Factor } & Avg. & $\begin{array}{c}\text { Standard } \\
\text { Deviation }\end{array}$ \\
\hline Not considering regional culture & 4.64 & 2.87 \\
\hline Implementation of SPI project on a large scale & 5.75 & 2.39 \\
\hline Lack of training & 6.19 & 1.91 \\
\hline Lack of implementation strategy & 6.40 & 2.11 \\
\hline Lack of infrastructure resources & 6.86 & 1.59 \\
\hline Lack of financial resources & 6.90 & 2.10 \\
\hline Lack of SPI project management & 6.95 & 2.13 \\
\hline Lack of human resources & 7.52 & 1.66 \\
\hline Not considering organizational culture & 7.60 & 1.38 \\
\hline
\end{tabular}

Table 9 shows the Organizational Factors category. Five factors were more frequently identified by the respondents as being critical to the abandonment of SPI: High turnover (7.0); Lack of awareness of the benefits of the improvement project (7.14); Lack of alignment between business and the goals of the improvement project (7.43); Lack of clarity of the goals of the project and (7.38) and Lack of understanding of the return on the investment (7.52), with averages up to 07 . The other factors had averages higher than 06 . Therefore, they are also factors that should be taken into consideration regarding the continuity of improvement programs.

TABLE 9. Critical Abandonment Factors: Organizational.

\begin{tabular}{|l|c|c|}
\hline \multicolumn{1}{|c|}{ Critical Abandonment Factor } & Avg. & $\begin{array}{c}\text { Standard } \\
\text { Deviation }\end{array}$ \\
\hline $\begin{array}{l}\text { Lack of formalism of functions and } \\
\text { responsibilities }\end{array}$ & 6.48 & 1.97 \\
\hline Inadequate communication & 6.76 & 1.79 \\
\hline High cost of SPI & 6.81 & 1.60 \\
\hline High turnover & 7.00 & 1.89 \\
\hline Lack of awareness of benefits & 7.14 & 1.71 \\
\hline Lack of clarity in SPI goals & 7.38 & 1.28 \\
\hline Lack of alignment between business and SPI & 7.43 & 1.60 \\
\hline
\end{tabular}


Lack of understanding of return on investment

7.52

1.83

\section{CONCLUSION}

Studies on the successful implementation of software process improvement programs have been the focus of researchers in the past two decades. However, the reasons why these companies end up maintaining or abandoning these initiatives is a field that has not seen a great deal of research. Thus, this study sought to bridge this gap. The research concludes that the continuation or abandonment of software process improvement programs depends critically on 13 factors, namely: i) motivation and acceptance of change; ii) support, involvement and commitment; iii) technical and personal competencies; iv) strategies for SPI; v) resources and communication; vi) goals; vii) organizational structure; viii) policies; ix) return on investment; $\mathrm{x}$ ) leadership; xii) adequate external consultancy services and; xiii) processes.

The study also found that the perception of SPI specialists is that in practice organizations do not pay due attention to these issues. This is probably one of the reasons why software development organizations abandon these programs.

The main limitation of this study is that it does not delve more deeply into the issues identified in the survey. There are some unanswered questions as: What does it happen to a company after the official evaluation using a maturity model? Why is not possible to identify a consistent evolution in maturity levels? Do companies abandon only the official evaluation process or abandon the overall improvement program? Do they abandon completely the implanted process or just parts of it?

For this purpose, it would be necessary to conduct a deeper study of the appraised software organizations to understand why these companies maintain and why they abandon software process improvement programs. Therefore, the next stages of this work will involve conducting a case study of the appraised software companies to assess the findings of this exploratory study in practice. Our preliminary case studies with the organizations showed some similar factors.

In future studies, it would be interesting to investigate how the maintenance of these SPI programs occurs in practice, i.e., looking at companies that continue their active appraisals and companies whose appraisals are overdue.

\section{REFERENCES}

[1] Sommerville, I., Software Engineering. 9th ed. Pearson Prentice Hall, 2011.

[2] A. Fuggetta. Software Process: a roadmap. In Proceedings of the conference on the future of software engineering - international conference on engineering, Limerick, Irlanda, 2000, p. 25-34.

[3] G.M. Kituyi and C. A. Amulen. Software capability maturity adoption model for small and medium enterprises in developing countries, In The Electronic Journal on Information Systems in Developing Countries EJISDC, v.55, n.1, p.1-19, 2012.

[4] CMMI PRODCUT TEAM. CMMI for Development. (CMU/SEI-2010TR-033). Versão 1.3. Pittsburg: Software Engineering Institute Carnegie Mellon University, 2010.
[5] Sociedade para Promoção da Excelência do Software Brasileiro (SOFTEX). Guia Geral MPS de Software - 2016. Disponível em:< http://www.softex.br/mpsbr/_guias/default.asp>.

[6] Secretaria de Economia do México - SEM. Modelo de Processos para la Industria de Software - MoProSoft versión 1.3, Agosto de 2005. Disponível em: http://www.comunidade.moprosoft.com.

[7] Lepments, M.; McBrid, T.; Ras, E. Goal alignment in process improvement, In the Journal of Systems and Software, v.85, p.1440 1452, 2012.

[8] Elm, J.; Goldenson, D. The Business Case for Systems Engineering Study: Detailed Response Data. (CMU/SEI-2012-SR-011). Software Engineering Institute, Carnegie Mellon University, 2013. http://www.sei.cmu.edu/library/abstracts/reports/12sr011.cfm.

[9] Kalinowski, M.; Weber, K.; Franco, N.; Zanetti, D.; Santos, G. Results of 10 Years of Software Process Improvement in Brazil Based on the MPS-SW Model. In Quality of Information and Communications Technology (QUATIC), 2014 9th International Conference, p. 28-37, Sept. 2014.

[10] Dyba, T. An Empirical Investigation of the Key Factors for Success in Software Process Improvement. IEEE transactions on software engineering, vl. 31, n5, p. 410-424, May 2005.

[11] Khan, A. A. ; Keung. J. Systematic review of success factors and barriers for software process improvement in global software development . IET Software (Volume: 10, Issue: 5, 102016 ). DOI: 10.1049/iet-sen.2015.0038.

[12] Bayona, S.; Calvo-Manzano, J.A.; Feliu, T.S. Critical Success Factors in Software Process Improvement: A Systematic Review. International Conference on Software Process Improvement and Capability Determination - SPICE 2012: Software Process Improvement and Capability Determination pp 1-12.

[13] Almeida, C. D. A., Albuquerque, A. B., Macedo, T. C. "Analysis of the continuity of software processes execution in software organizations assessed in MPS.BR using Grounded Theory", XXIII Software Engineering and Knowledge Engineering, Miami 2011.

[14] UskarcI, A., Demirörs, O. Do staged maturity models result in organization-wide continuous process improvement? Insight from employees. In Computer Standards \& Interfaces 52 (2017) 25-40.

[15] Sociedade para Promoção da Excelência do Software Brasileiro (SOFTEX). Guia de Implementação - Parte 11: Implementação e Avaliação do MR-MPS-SW:2012 em Conjunto com o CMMI-DEV v1.3. Agosto, 2012. Disponível em:< http://www.softex.br/mpsbr/_guias/default.asp>.

[16] Kitchenham, B. Procedures for Performing Systematic Reviews. Software Engineering Group, Keele University, Keele, UK, July, 2004.

[17] Strauss, A.; Corbin, J. Basics of Qualitative Research, $2^{\mathrm{a}}$ ed.: Sage Publications, Thousand Oaks, London New Delhi, 1998, 312p.

[18] Forza, C. Survey research in operations management: A process-based perspective. International Journal of Operations \& Production Management, v.22, n.2, p.152-194, 2002.

[19] Kitchenham, B.; Pfleeger, S.L.P. Principles of Survey Research: Parts1-6. ACM SIGSOFT - Software Engineering Notes, 27, n. 1-6, Setembro 2002.

[20] Parasuraman, A.; Berry, L.L.E.; Zeithaml, V.A. SERVQUAL: A multiple-item scale for measuring consumer perception of servisse quality. Journal of Retailing, York University, 1998. 